\title{
Medical Image of the Week: CMV Cytopathic Effect
}

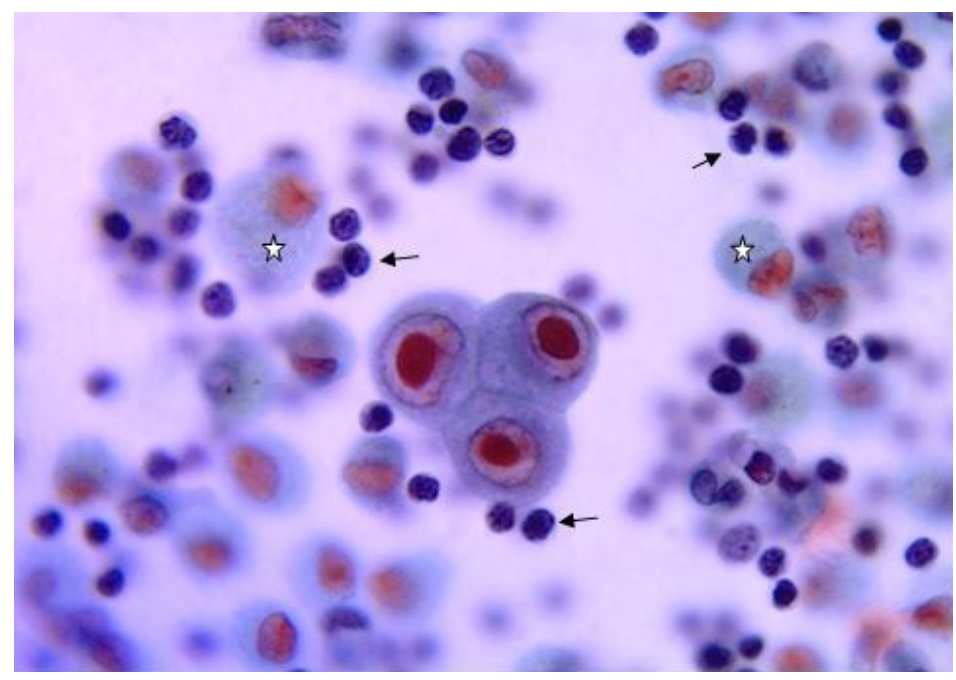

Figure 1. Cluster of 3 large cells, most likely infected type II pneumocytes, with a single prominent red stained nuclear inclusion surrounded by a clear halo. This appearance is the "cytopathic effect" needed to definitively diagnose active CMV infection.

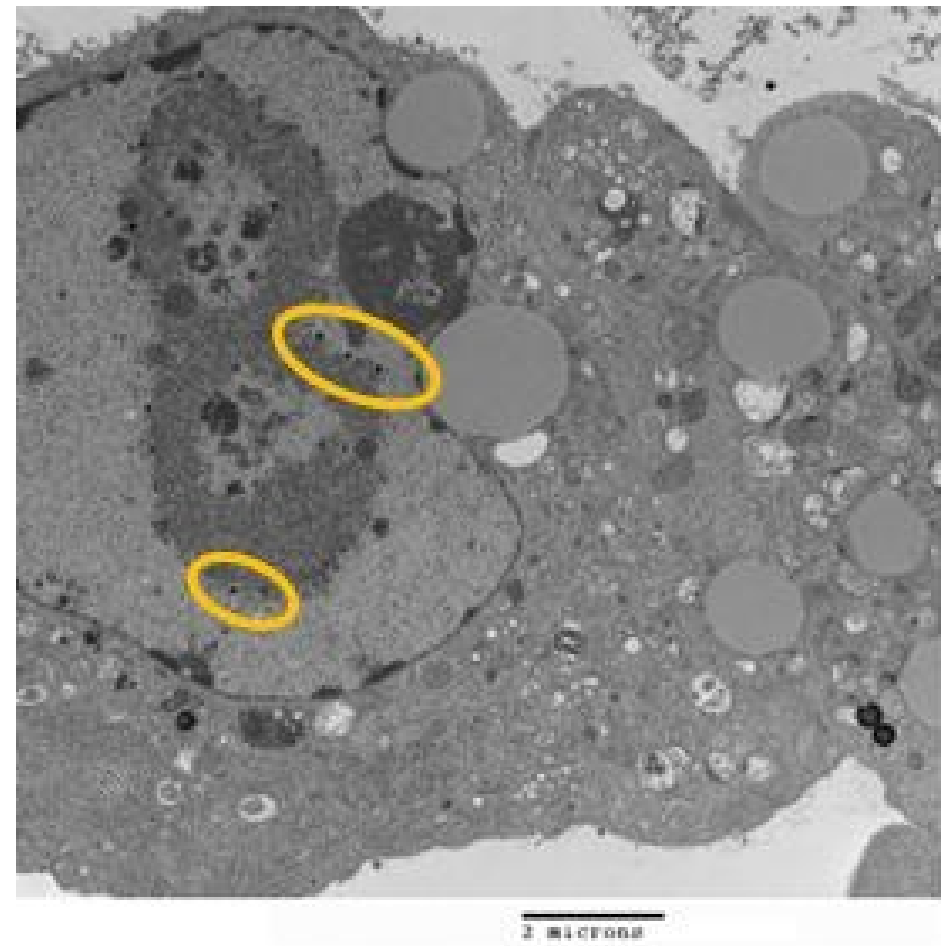

Figure 2. Electron microscopy (8800x) of an infected cell showing cytomegalovirus $(\mathrm{CMV})$ virions within the nuclear inclusion (small black dots encircled). 
Bronchoalveolar lavage (BAL) was performed on a 45-year old man with a history of treated mycosis fungoides and Sézary syndrome, who presented with fever and pulmonary infiltrates. BAL Papanicolaou stain (Figure 1, 400x) showed single cells (lymphocytes, arrows and alveolar macrophages, stars) and a small cluster of 3 large cells, most likely infected type II pneumocytes, with a single prominent red stained nuclear inclusion surrounded by a clear halo. Nuclear chromatin was marginated on the nuclear membrane creating this "owl's eye" appearance. In vitro, infected cells show cytomegalovirus (CMV) virions within the nuclear inclusion (Figure 2, small black dots encircled, 8,800x)

The "owl's eye" appearance (figure 1) is the "cytopathic effect" needed to definitively diagnose active CMV infection. While cells infected with adenovirus or herpesvirus may have nuclear inclusions, the cells typically are much smaller. CMV was cultured from the BAL, and no other pathogen was identified by cytology or culture. Quantitative PCR on blood for CMV was $144359 \mathrm{IU} / \mathrm{ml}$.

Afshin Sam, MD; Felicia Goodrum, PhD; Robert Ricciotti, MD; Ken Knox, MD and Richard Sobonya, MD Departments of Medicine, Immunobiology, and Pathology University of Arizona Health Sciences Center

Tucson, AZ 